\title{
Editorial
}

\section{Depression in Clinical Practice}

\author{
M G Rabbani
}

\begin{abstract}
What is at the root of depression? What is its essence? There are several possible answers to this question, depending on whether you focus on the semiology or pathogenisis of the illness.
\end{abstract}

If we look at the symptoms, some consider that depression revolves around a deceleration of all a person's functions. This is because the patient not only experiences a slowing down of his motor function, actions, gestures, and nonverbal expression, but also a slowing down of his ideation, speech, and even his neurovegetative functions, such as cardiac and digestive function. The digestive system secretes less saliva and digestive juices amongst other things, which partly explains the resulting anorexia and weight loss. in severe depression, the patient also experiences altered temporal awareness. with time seeming labored, crawling painfully by. When listing the symptoms suffered by depressive patients in a number of countries across the world, this general slowness seems to be the most common.

Others feel that anhedonia, a difficulty or sometimes an inability to feel pleasure, lies at the true heart of depression. Anything that previously brought pleasure, joy, or satisfaction becomes devoid of interest, even painful, for the sufferer, for the sufferer. It is therefore futile to force a depressed person to partake in pleasurable activities, since not only will he be unable to draw pleasure from them, he will also feel guilty about not sharing the enjoyment of those around him. Anhedonia is also accompanied by a fall in the patient's pain threshold, which explains the many pains of which a depressive person complains, as well as the analgesic effects of antidepressants.

Finally, the oldest symptom recognized as being central to the state of depression is sadness. In fact, the link between depression and mourning was made a long time ago, especially when it involved the loss of a loved-one or a situation valued by the patient. This can be seen clearly in these lines penned by the French poet Gerard de Nerval:

Md. Golarm Rabbani

Director-cum-Profaessor

National Institute of Mental Health, Dhaka.

\author{
I am the Man of Gloom - theWidower - the \\ Unconsoled, \\ The prince of Aquitaine, his tower in ruins: \\ My sole star is dead - and my constellated lute \\ Bears the Black Sun of Melancholia.
}

Others feel, with just cause, that the trigger of depression is a disrupted circadian rhythm. An abnormal rhythm, due for example to working night shifts, will affect a person's cognitive function, his sleep pattern, and sometimes his mood. When a person is depressed, his psychobiological circadian rhythm of sleep, appetite, and physical activity becomes unbalanced. This is the cornerstone of a process that assaults the patient's brain and so worsens the depression.

Yet other authors say that an attack of depression is a sort of acute aging crisis. A young person who is stuck in the past and cannot think of the future, who is unable to look forward to anything, who suffers restless and broken sleep, who has lost his appetite and muscular strength and who is sometimes unable to perform sexually, is a person who is beyond his years. A person suffering from acute depression walks slowly, hunched over, with increased response times. He complains of excessive fatigue and the slightest effort takes it out of him. In fact, it is hardly a metaphor to say that an attack of depression is a sort of acute aging process. Do we not say of a person who has had a severe psychological shock and who then falls into depression that he has aged 10 or 20 years in just a few days or weeks? it is also interesting to note that a depressed person's brain has reduced levels of brain- derived neurotrophic factor and other neurotrophic factors. something that is also seen in some elderly persons.

These aspects and many more are discussed in the excellent articles such as core symptoms in major depression, depressed mood; a hallmark symptoms of depression, circadian rhythms: evolution of a core symptom of depression respectively by Hans-Jurgen Moller et al., Per Bech, and Goran Hajak in recent years. They clearly demonstrate that depression, despite its simple presentation, deserves greater study of its diversity and multiple facets, which differ vastly from one person to the next. 